\title{
An Experience on Environmental Education Based on Respect-Reduce-Reuse-Recycle in a Village Primary School in the Marche Region, in Italy
}

\author{
Carlo Santulli* \\ Università degli Studi di Camerino, School of Science and Technology, Via Gentile III da Varano 762032 \\ Camerino, Italy \\ E-mail: carlo.santulli@unicam.it \\ Tania Pallottini \\ Primary school “Carassai”, Via XX Settembre, 23, 63063 Carassai (AP), Italy \\ E-mail: tania94.p@gmail.com \\ Giuseppina Gentili \\ Primary school “Carassai”, Via XX Settembre, 23, 63063 Carassai (AP), Italy \\ E-mail: gius.gentili@libero.it \\ Claudio Ortenzi \\ Università degli Studi di Macerata \\ Dipartimento di Scienze della formazione, dei Beni culturali e del Turismo, 62100 Macerata, Italy \\ E-mail: claudio.ortenzi@unimc.it
}

\section{The research received no external funding}

\section{Abstract}

The importance of environmental education is widely recognized worldwide: an important objective is that the citizens are accustomed to apply the best available practices in their life, while asking the administration and the government to gradually enforce measures leading to a reduction of the environmental impact and to a more sustainable lifestyle. This requires a formation starting at an early age: however, in Italy the relevant indications from the National Curriculum are still limited and do not suggest explicitly the performance of any practical activity, tailored on the specific school setting. This inadequacy of the Curriculum becomes particularly apparent in cases where other concerns are present, for example the areas in the Marche region affected by the 2016 earthquake: here, the need to resume a day-by-day routine put a kind of "damper" on other questions, such as environmental issues. This had an effect also in children's life: on this question, school needs to take a stand, which is the objective of this study. This work concerns an approach to environmental education in a multi-classes primary school context (age 6-10) in a small village school, located in the Central Apennine in Italy. This is performed through an experience carried out by investigating the behavior towards waste production of the community, as perceived by children at school. It is therefore articulated through the application of 4R (Respect, which encompasses Reduce, Reuse and Recycle) applying and extending the indications from the Italian National Curriculum. The project leads also to an experience of self-production of objects by the use of waste, to improve their awareness of the possibilities included in their upcycling. Feedback on the experience is finally acquired from the children and discussed, especially in the sense of creating future citizens with a more sensible and reasonable behavior towards the environment and leading possibly to zero-waste strategies in their family and work setting. The data were analyzed using thematic analysis and different themes about waste production were singled out.

Keywords: Environmental education, reduce-reuse-recycle, respect, DIY materials, good practices

DOI: $10.7176 / \mathrm{JEP} / 11-15-04$

Publication date:May $31^{\text {st }} 2020$

\section{Introduction}

One of the present concerns in primary education is introducing children to an awareness of environmental issues through an appropriate education in the subject (Arani et al., 2016). The ultimate goal of environmental education is promoting a responsible behavior to be possibly communicated and extended to the whole community the children are living in (Gotch and Hall 2004). A promising approach to this aim is eco-management, which can be synthesized by the 7Rs "Reduce, Reuse, Respect, Reflect, Rethink, Recycle and Redistribute", as proposed by OMEP (World Organization for Early Childhood Education) in 2010. The 7Rs represent a tool to organize early education to understand and put to practice strategies for sustainable development (Duncan 2011). Moreover, these specified dimensions would completely encompass the three pillars (economical, socio-cultural and environmental) of sustainability, providing also space for their mutual integration and in some cases superposition (Kahriman- 
Ozturk et al., 2012).

More specifically, the 7Rs allow translating concepts of sustainable development into practice. This is useful, since sustainability may not be easy to be explained in theory, as it may involve some degree of technical knowledge, while on the other side it is important to introduce it, in the form of "good practices" into the daily routine of an early education context (Summers 2003). A starting point that may represent a useful input for environmental education is that children have an instinctive concern for the environment, using which the teacher can build a more structured knowledge of the real problem (Leeson 1997). Discussion has also been raised about the possibility of "learning by doing" in the specific case of environmental education, therefore using practices that can involve active children's participation (Barraza 2001).

In the Italian school, the possible implementation of environmental education into teaching at a primary school level makes it essential to start from the indications offered by the most recent National Curriculum. It is noteworthy that in this document, environmental education is not explicitly mentioned, most possibly suggesting that the level of knowledge of the children is not sufficient to turn directly to the subject. However, a number of indications are given in the National Curriculum (Annali della Pubblica Istruzione 2012) that can be purported to be related with environmental education. To start with, the general objectives of the primary and lower secondary school in Italy, therefore age 6-13, are: promoting the sense of responsibility of the pupil; foster an active role in his/her own learning; have a function of orientation; favor active citizenship and awareness; reinforce creativity and critical spirit; promote mutual respect and collaboration.

Among these general goals, the one most closely related to environmental education appears to be favoring active citizenship. Therefore, participating to the local community implies for children to be involved in common practices for sustainability, among which the most significant, also because continuously run over the year, is the differentiated collection scheme, most recently implemented according to hierarchy exposed in EC 98/2008 directive. The directive foresees nonetheless also the application of possible strategies for the reduction of waste, which is the highest and most virtuous "step" of the hierarchy itself. In psychological terms, for waste not to be produced value needs to be conferred upon it, a process which is defined as "upcycling" (Mc Donough and Braungart 2013). One possibility to apply this practice into school can be using common waste e.g., such as food waste (e.g., fruit skins, eggshells, etc.), to make small objects in Do-It-Yourself "bioplastics" (Cecchini 2017). This has been applied with some success e.g., into a children museum's (Explora, Museo dei Bambini, in Rome: https://www.mdbr.it/en/ ) context, as described in Santulli and Lucibello 2018. This project builds partially on that experience, concentrating on the issue of introducing environmental education as a self-standing subject into a primary school situated in an isolated context. In this setting, the very survival of the school may appear problematic in the longer run, also for specific circumstances (depopulation, due to the crisis of agricultural activities, and consequences of 2016 earthquake), although this would lead to negative social consequences for the village itself.

The main challenge of this work into introducing children to sustainable development towards practicing upcycling, in order to reduce waste, and differentiated waste collection, to correctly dispose of it, is integrating it in the setting of a village over the hills in the Marche region, which was quite depopulated as the consequence of an earthquake in 2016. This makes it not particularly easy to implement this kind of practices still at the period of study (January-March 2019), in which the situation was gradually coming back to normal life, after reconstruction and restoration of the damaged houses. The 7R approach was tentatively preserved, applied though only through those which are most relevant to the problem under study, therefore Respect, Reduce, Reuse and Recycle.

\section{Project, setting and participants}

The aim of this work is to correlate environmental awareness in children to the observation of issues present in the local community, concentrating on a practice that is well known as a concept to children from an early age, such as differentiated waste collection. Two workshop activities were planned, one connected to differentiated waste collection i.e., the creation and decoration of differentiated waste bins, created by the children, while the other is more concentrated on the valorization of waste through upcycling, starting from a secondary raw material obtained as waste in the school canteen i.e., egg shells. The whole experimentation has been created in the understanding that naïve approach the children already have and are able to apply to waste disposal and management could be also brought, without being dismissed, to obtain more structured information, able to be applied at school as multidisciplinary knowledge, and in the local setting even as improvement of environmental management from the community.

The experimentation has been realized in the primary school in Carassai, a village with 1012 residents in 2018, according to Wikipedia, not far from Ascoli Piceno, in a school complex detached from the Istituto "G. Sacconi” di Montalto Marche - Rotella during year 2018-19. This primary school had during that year 23 pupils, organized in two mixed-classes, one including eight Year 1 pupils and one Year 2 pupil, who has a dedicated teacher only for four hours a week, and another including eleven Year 4 pupils and three Year 5 pupils. There are no Year 3 pupils. In the experiment, when mentioning the pupils' names, they are replaced by pseudonyms. 
School time is from Monday to Saturday, starting at 8.20 and ending at 12.50. The total number of teachers is five: the two main teachers for the respective mixed-classes, the history and geography teacher, the religion teacher and the special needs teacher.

The activities were planned for the whole school and therefore the idea is that they could be adapted to different ages (from 6 to 11 years old). These fit into the Curriculum of the Institute, for the reason that some Environmental Education lessons had already be planned. The school takes part into two other projects dealing with these themes, in particular one realized by "Marche a rifiuti zero" (Marche to zero waste), and the other by "Fondazione Ambienta" (https://www.fondazioneambienta.it ).

\section{Design of the Experience}

\subsection{General structure}

The design reflected the fact that for some children this was the first time they were dealing with themes related to the environment. The naive approach selected implied reviewing in general the environmental problems that are affecting our life at the moment, then concentrating on those that are closer to the children. Problems have been evidenced about this approach, because it is obvious that children normally try to answer the question the interviewer poses and this is not naïve, although it might clash with the limited information they dispose of (Hall 1996). Yet, the intention was to make the subject more concrete and factual. This required a reflection on the dayby-day actions performed by the children and their families, concentrating on waste disposal and the issues/opportunities it can create. The method started from the naive knowledge the children had, coming then to interactive explanations and workshop experiences.

The activities organized revolved, as mentioned already, around the Respect, Reduce, Reuse and Recycle. The idea was that the $\mathrm{R}$ of Respect would encompass the other three, which follow the waste disposal hierarchy formalized by EU 98/2008 directive. In other words, a sense of Respect would allow taking the most suitable actions for the preservation of the environment, starting from the one the children and their families most frequently experience, therefore their village setting.

\subsection{Definition of goals and objectives}

As mentioned already, no specific section dedicated to environmental education is present in the Italian National Curriculum, which is an historical exigency, especially in the light of recent European legislation, yet never fulfilled (Malatesta and Camuffo 2007). In contrast, it is inserted as a subject in other disciplines, namely geography and science, yet it is not intended for a study into depth. The idea of this project was also to highlight what is the potential of environmental education based on the Reduce-Reuse-Recycle method for learning the two aforementioned disciplines and orient the project to the goals and objectives, present in Italian National Curriculum, which are exposed in Table 1.

Further objectives are also proposed, of more general and interdisciplinary nature, which can be possibly reached through this project:

- Succeed in using and relating competencies developed in different disciplines for the realization of the same task;

- Realize artifacts with the use of waste materials, employing creativity and fantasy;

- Select the main information and organize them sensibly in realizing the final authentic homework (summarizing booklet);

- Be able to clearly expose the main concepts and the specific passages of the project realized.

\subsection{Competences acquired}

The competences acquired concerned alphabetic literacy skills, mathematics, with particular reference to measurements, science, technologies, with particular reference to materials, and digital competencies. Beyond this, they also acquired personal, social and self-learning skills and a capability to improve their citizenship belonging, together with the ability of thinking of entrepreneurship. This led also to a better self-awareness and cultural expression.

A number of mediators were also employed during the meetings: these included symbolic, iconic, active and analogical ones, the last two especially in the Reduce and Recycle activities.

\subsection{Details of the experience structure}

The whole experience is structured over three main activities, which are detailed in this Section. The idea is that each activity is based upon Reduce, Reuse or Recycle, while Respect is considered in all of them. The three activities are in particular:

- Watching excerpts of E-wall and film on the plastic island, interviews to the children and Powerpoint presentation on materials degradation (Reduce) 
- $\quad$ Experience of production of DIY materials from waste (Reuse)

- Realization and decoration of bin for differentiated waste collection and explanatory booklets selfproduced (Recycle)

\subsection{Method for evaluation}

The method was centered on comparing the naïve knowledge about the environment present in the children with a structured one, which is embedded in the Reduce-Reuse-Recycle hierarchy, with the Respect aspect to indicate the sense of the strategy. The importance of this evaluation is focused on understanding the main difficulties in applying the hierarchy. In return, children are able to offer to the community innovative ideas and suggestions. These two types of results are therefore expected: issues and visions, in a sense. Of course, the children have got their own ideas about what the words indicating the 4Rs mean and these come out during discussion.

Since the sample is very sparse in terms of age and as a whole not very numerous, but shares the values and the needs of a small community, only qualitative indications can be sorted out. These are indicated with respect to the single $\mathrm{R}$, and then a summary is tried, especially to indicate what could be the possible improvement coming from the children to the development and the resilience of the community, to which the environmental practice contribute.

\section{Activities development}

\subsection{Reduce activity}

The Disney Pixar "Wall-e" movie, of which excerpts are shown, deals with two robots, Wall-e and Eve, clearing the Earth from waste: this represented a different way in animation films to look at nature as a resource to be preserved (Whitley 2012). From the film, the main idea is taken that waste is a problem and that the robot feels the responsibility to dispose of it correctly.

The first stimulus question was mainly intended at verifying the naïve knowledge of children: "In your opinion, is it possible to get to a situation like that? Why so?" on which a discussion was started, from which, as easily predictable, arouse the need to better concentrate on what "pollution" really means, hence evolving from children's naïve knowledge, trying not discourage them from expressing their perspective and vision.

This required the vision of a PowerPoint dealing with the different types of pollution (of water, air and soil) (Figure 1), the reasons why pollution has disfigured the natural environment and the respective times for decomposition of the different materials. After this, the children were invited to get up and comment on the environment in which we are, starting a reflection from the very setting we are in, yet evolving to consider that in some places the situation appears instead to be very similar to the one described in "Wall-e" film.

Post-its are stuck to the whiteboard, as in Figure 2, and a discussion is then set, building further on the stimulus question: "Is it possible that our Earth can get to that point?", followed after some answers by "What is pollution?" to allow reflecting on the relation between our behavior and the environment.

All the doubts were then clarified and a further discussion was generate on the duration of waste items (also "use-and-throw" ones) that we produce, since a considerable curiosity about this aspect was experienced, Children were subsequently invited to stand up, go by the windows and watch the panorama in front of them by the stimulus question: "What do you see out of the windows?", to verify their previous mental perception of local environment. The actual landscape from the classroom windows is shown in Figure 3.

After this reflection, the children are presented with a video on sea pollution, concerning the so called "plastic island": https://www.youtube.com/watch?v=KpVA4ISxPIk) Following the discussion provoked from the vision, a further question is proposed, in more general and ethical sense: "What can we do to maintain our place as nice as it is? And to avoid situations like this one?". This introduced the second stimulus question, which includes searching for proposals: "What can humans do not to pollute? To avoid that, what we saw would happen again?". In this case, answers and proposals were written on the blackboard with the idea that this would be what is going to be presented to the wider village's community, starting from the families.

In the final phase of the activity, the 4 "Rs" are introduced, starting with the more comprehensive one, Respect and its connection with Reduce, in a brief Powerpoint presentation, shown in Figure 4. It is briefly explained that this means respect for people, but also for what surrounds us, therefore for the environment. After this brief statement, a post-it has been given to every pupil and they were asked to write or to draw a situation of respect towards someone, something or the environment itself.

This allowed better specifying the whole significance of the 4Rs, which are more clearly specified into: Respect the environment; Reduce waste; Reuse, therefore using as much as possible the things we have, even in different ways. Recycle, and preparing to it by knowing better differentiated waste collection. In particular, the discussion was triggered by: "What can we reduce to create less waste and less dirt for the environment?". Proposals were collected, which soon concentrated on different types of waste, and post-its are stuck by pupils on the whiteboard (Figure 5). 


\subsection{Reuse activity}

The reuse activity was based on the production of DIY materials from waste upcycling. With this aim, a recipe was prepared, which was deemed simple, therefore with few ingredients, and adapted to the context. In practice, it needed the use of eggshells broken into fragment in a mortar. These were directly collected from waste in the school canteen, and they were added with corn starch, vinegar and water.

A number of previous tests allowed improving the recipe and adapting it to the experimentation needs. Molds for biscuits were used to realize many different forms and making it more interesting and amusing. After this, the question of the function of the objects was posed. A screw was therefore inserted in the mold, to create a hole, so that, once cooked, demolding of the object would leave a hole to insert a string. The final object obtained was therefore a pendant/key ring, according to the children's intentions. Then there was the possibility to personalize the mixture with the addition of food coloring, or else, for black and yellow colors, of exhausted coffee grounds or curcumin. The whole of it would need to be easily biodegradable once decomposed and therefore easily disposable in the bin for organic waste.

In the introduction, the children were introduced to the fact that two types of re-use exist:

1) Using more times the same object, which implies respecting it and repairing it whenever possible, avoiding at the same time to buy "single use" objects. This habit to be avoided has been related elsewhere with the presence of the "plastic ocean" (Johnson 2019).

2) Offering a new life to materials and even to waste through a procedure called "Creative re-use"

The children were then presented with some examples of creative re-use for the realization of toys, decorations, pen holder, musical instruments, etc., adding that they will perform two experiments of "creative reuse", one aimed at the creation of funny and playful objects and the other by decorating waste collection bins.

A brief introduction to experimentation has been given, on the different problems to be encountered during molding and cooking or modeling and drying the compound. Some emphasis was also put on the fact that there is avoidable waste, such as apple skin, which is edible or can be used in other ways in cooking, and waste that cannot be easily avoided, such as it is the case for chestnut peels (and eggshells of course). After this, some considerations have been made on the possible name for the DIY material, starting from a proposal, Mister Egg.

Following this, the DIY material with eggshells has started to be created. The recipe was presented on a Powerpoint slide projected during the experimentation and kept on the interactive whiteboard screen for reference. A number of operations were necessary, disposing the ingredients for the recipe, weighing them and mixing them in the bowl, as depicted in Figure 6. Then the children, divided into couples, would receive a part of the compound and select a mold and a color to be used.

The recipe for 25 molds was the following

- $\quad 350$ grams of fragmented eggshells

175 grams of cornstarch

- $\quad 130$ grams of water (add more of it during mixing if the compound is too hard)

23 grams of vinegar

The last part of the activity was the selection of the name for the DIY material. The children were asked for it, every child could also propose more than one name. A collection of the final objects obtained is shown in Figure 7.

\subsection{Recycle activity}

The recycle activity has been mainly centered on the practice of differentiated waste collection, as preliminary for recycle. Before the activity, the classes were carrying our only the collection of paper, all the rest was going in the undifferentiated bin: the two bins were present in both classrooms. In contrast, the paper bin was in the corridor, out of the classes, therefore seldom used in practice. No bin was organic waste was present in the school.

The activity was prepared by collecting the plastic waste produced by the two pluriclasses. A container to collect them has been left on place.

Before the activity, two different pieces of homework have been given to the two pluriclasses.

1. Homework for Year 1/Year 2 pluriclass:

Make a drawing on how at your home differentiated waste collection is run.

Remember to draw and color bins and what you can find inside them

Which one has more waste inside?

2. Homework for Year 4/Year 5 pluriclass:

With the assistance of your family, please answer to the same questions and draw in which way the differentiated waste collection is carried out in your home.

Write then why, in your opinion, waste is differentiated and what is the importance of this action. Does your family perform differentiated waste collection?

Which containers do they use and how are they? Please draw them. What do you put in there? Give some example for every container. 
Are there some fixed days for collection?

Who is in care of differentiated waste collection?

These documents served as preparatory phase for the Episode of Situated Learning (EAS in Italian), which proved effective for a higher level of engagement and learning of children (Terrenghi et al., 2019). All children were asked to collect plastics, which they will have produced along the whole week, inside a big cardboard box. Two boxes were then left, one for every pluriclass. One week after, waste collected from class activities would have been selected to serve for the realization of an artifact. Slides showing some indications for differentiated waste collection were presented to the children.

To carry out the operational phase, four groups were formed of either four or five children, mixing children of the two pluriclasses.

The work was carried out by assigning to each group had one specific family of materials to be differentiated, namely paper, plastics, organic and general waste.

With help from cards filled at home and adding to that material supplied by the teachers, they would have realized some posters (A3 format) to be hanged to the wall close to the collection bins already present at school. In the two classrooms, the plastic bin would have been added and in the school front room also the one for organic waste. Each group was in charge of creating posters, which would introduce the main information to assist in correctly performing the differentiated waste collection, making some cards, indicating precisely which materials were to be thrown there and which weren't. The posters would need to be well clear and visible; therefore drawings and creative parts were to be added, according to the suggestions given by the organism in charge of the collection, PicenAmbiente (http://www.picenambiente.it/) in their leaflets, which were passed to the children and which content was summarized in a Powerpoint presentation, presented in Figure 8.

A further phase involved weighing the amount of plastic collected in a period of two weeks in the school. First some guesses were done by the children about the final weight, and then measurements have been carried out.

Also in this activity, a phase of creative re-use was envisaged, by decorating two different cardboard boxes by using a part of the plastic collected during the week and then bonding them to the bins (Figure 9). Finally the bins have been completed with writings, particularly on the amount of plastics collected.

The final phase involved the creation of a booklet in an "authentic task". This is typical of environmental education approach at this level, especially whenever the involvement of the whole community is supposed to be realized, at least on the background (Robertson and Lee 2009). This has been formed by folding two A4 sheets in order to obtain eight pages and dedicate two pages each to any of the $4 \mathrm{Rs}$ of the project. Total freedom has been given about the choice of colors and the possibility to insert images of DIY materials and recipes, etc. An example of the result obtained is reported in Figure 10.

\section{Discussion}

The discussion would concern the whole of the experience, and especially the overall value of it for an approach to environmental education at the level of primary school. A general point regards the aspect that environmental education needs to have his place as a multidisciplinary subject, especially in view of a school well rooted into sustainable development and circular economy. The experience needs therefore a precise focus on this, which in principle the cycle Respect-Reduce-Reuse-Recycle offers, from what has been perceived during the time the project lasted.

What really this discussion would like to clarify is the answer from the pupils to the contents offered, bearing in mind the two specific characteristics of the setting, the first being having a small number of children with some age gap between them, about a half of them being aged 6-7, whilst the other half being 9-10. This has often required diversifying activities during the project. The second aspect is the collocation of the school being in a depopulated mountain area, which in principle would suggest that big environmental concerns would be perceived as remote or even not entirely relevant, given the absence of industrial and urban areas in the setting surrounding the school. This in another sense is of interest, because it pushes the experimenter to investigate which is the naïve knowledge about these themes the children have despite being quite isolated and then the possibility and interest they may have into going deeper into these subjects. Another challenge was the integration of the Reduce-Reuse-Recycle triad, which is well known and experimented in environmental education, into the Respect concept, which involves in particular the aspect of active citizenship.

The Respect concept proved easier to be related immediately to the Reduce one, especially through the fact that things have to be respected so to try to avoid becoming waste. As an example, a child even wrote on a post-it "I respect Lego bricks", which seemed odd at first to the classes, but demonstrated he/she had caught the connection between lack of respect for objects and likeliness for them to become waste. It proved therefore rather straightforward for children to reconnect to a kind of moral judgment the production of waste, especially plastics, which appears more evident in the communication, and may be also a slight bias in the experience was also present, especially thinking about the film of the "plastic island". Such as Paolo (Year 1) posed it "if you are naughty and 
throw things on the ground, the dirt stays there". A not obvious passage was passing from waste to pollution, yet in some cases the connecting point is the human activity (Elia, Year 4: "Pollution is such as...discharging sewage at sea, or going by car".

A few themes proved effective in inducing interest for the preservation of the environment, in particular discussion on biodegradability aroused a large number of questions about different materials and degradation times, whose relation with generation of waste appeared of easy comprehension. Differentiated waste collection was on the other side perceived as a good practice to be communicated to the families. Of course, and it would be hard to convey this to the pupils, this practice is a model tending to the management of waste from an optimal point of view and it depends also on the local conditions and as such it has been communicated to the children. There is obviously more attention on some types of waste than other ones.

The passage from the naïve knowledge to the more structured one has been signaled during the experimentation by the amazement on a few questions. In particular, it is important to mention that the weighing of plastics led, apart from the learning of measurement skills (for example, it allowed introducing in a simple way the question of setting the scale to zero, therefore to eliminate the tare weight from it), to some considerations on the real extent of the "plastic waste" issue. Other quantitative data to which the children showed interest were the respective times for biodegradation of materials, for example Davide (Year 2) said, showing his plastic bottle: "This small bottle can last up to a thousand years! That's a lot!"

In the long run, this could lead to considerations on the difference between the various materials, also in mechanical and physical terms, useful in teaching science and technology to children. Apart from plastics, other types of waste that are dumped and hardly ever collected were mentioned by a number of children, such as cigarette butts (quoting Marco (Year 1): "On the ground we find lots of cigarettes".

What has been found by the experiment is that children are entirely aware of the special characteristics of your environment, they often mentioned they were seeing out of the window trees, lawn and hills, although in some cases they gave an enhanced evidence to the possible presence of waste (Debora (Year 4): "I have seen lots of dirt and also the houses", Marco (Year 1): "Some small pieces of paper, which stayed there for a long time") and even concerns have been raised on the quality of tap water Lucia (Year 4): "At home it comes out white".

The attention to best practices was also highlighted in some cases and appear central to the children's experience (Edoardo (Year 4): "To sort it out, in Australia, I think there are places in which you bring empty plastics (sic)" and Valerio (Year 4): "When I went to Berlin, there were places in which you inserted the empty plastic bottle and they were giving you 10 cents back". Some considerations included for example Flavia (Year 4): "Do the differentiated waste collection", Noemi (Year 4): "Recycling" and "Throw things where you have to throw them". A risk in this way of reasoning is that an exceedingly large place is given to "recycling", because it feels "good", which is a risk signaled already in ecological behavior to families (Kinnaman 2006). In another sense, the connection between learning a "good practice" and the ability to perform recycling was clearly perceived.

In this sense, the production of DIY materials from waste allowed to make recycling a more concrete and factual process, which worked well, allowing rebuilding the link between children as users and refuse, which at first created a sense of despair, like something no longer used. It is worth noting that the whole of the experience followed the experimental method, based on measurements and a trial-and-error. This was applied in a number of circumstances via the prediction of the amount of plastic collected, the application of the recipe and the considerations on its success in the creation of the objects. The experience demonstrated in several situations the undervaluation of the facts: for example, the amount of plastic collected and the possibilities "embedded" in the refuse collected, as to create some objects of interest and even of election for children. A diffuse comment was about the presentation of the objects at the children's family, which suggested they were not only perceived as evocative, but also created in them a sense of pride for the achievement they have fulfilled.

\section{Conclusions}

The main results obtained from the experience are particularly concentrated on taking conscience of the role of materials and of their different potential. On one side, there is the difficulty in recycling, the persistence of materials as waste in the environment, their capability to pollute. Yet, on the other side there is the expressive potential of waste, as decoration of objects, such as bins, or as Do-It-Yourself gadgets: this is the way to rebuilding our relation with waste and seeing the opportunities into it, which is now referred to as "upcycling". The children demonstrated in general terms that they are very interested into good practices and in communicating them into the wider community, and easily grasp the connection between these and the preservation of the environment. As far as introducing environmental education at school, this appears to be necessarily connected with practical activities and the implementation of authentic tasks, with a consistent aid from the audiovisual technologies.

The future perspective concerns possible actions for the introduction of environmental education in Italian schools in a more structured way, which needs to involve practical activities. This is faced on the one hand to the scarcity of resources, but on the other side can rely on the wider involvement of the whole community, which is ultimately one of the objectives of formation, especially at a primary school level. This occurs at a time in which 
movements and class actions for reducing environmental impact are particularly dynamic, so that also many children appear well aware of these issues, for example as regards limiting plastics use, and extending life duration of materials and objects, hence reducing the production of waste over time. This will result ultimately also in a revaluation of the zero-km "craftsmanship" experience, as opposed to globalised production, which in the specific case of Italy, but also of many other countries, represents a strong cultural experience, able to connect environmental sustainability to other disciplines, such as history, geography and technology.

\section{References}

Annali della Pubblica Istruzione. (2012) Indicazioni Nazionali per il curricolo della scuola dell'infanzia e della scuola primaria. Periodico multimediale per la scuola italiana a cura del Ministero dell'Istruzione, dell'Università e della Ricerca.

Arani, M.H, Bagheri, S., Ghaneian, M.T. (2016), The role of environmental education on increasing the awareness of primary school students and reducing environmental risks, Journal of Environmental Health and Sustainable Development. 1(1), 1-11.

Barraza, L. (2001) Environmental Education in Mexican Schools: The Year primary Level, Journal of Environmental Education, 32 (3), 31-36.

Cecchini, C. (2017) Bioplastics made from upcycled food waste. Prospects for their use in the field of design, Design for Next Environment, 2017, S1596-S1610.

Directive 2008/98/EC of the European Parliament and of the Council of 19 November 2008 on waste and repealing certain Directives.

Duncan, E. (2011). Report Part 2 - ESD in practice. Norway: OMEP (Organisation Mondiale Pour L'Éducation Préscolaire).

Gotch, C., \& Hall, T. (2004). Understanding nature-related behaviors among children through a theory of reasoned action approach. Education Research 10 (2), 57-177.

Hall S, Helping primary school pupils to understand the relationship between needs, wants, and technology, Journal of Design and Technology Education, 1 (1), 1996, 37-40.

Johnson, R.B. (2019), THE PLASTIC OCEAN: An art educator's interpretation. Thesis, Georgia State University, 2019. https://scholarworks.gsu.edu/art design theses/250

Kahriman-Ozturk, D., Olgan, R., Guler, T. (2012). Preschool Children's Ideas on Sustainable Development: How Preschool Children Perceive Three Pillars of Sustainability with the Regard to 7R, Educational Sciences: Theory and Practice, 12 (4), 2987-2995.

Kinnaman, T. (2006), Examining the justification for residential recycling, Journal of Economical Perspectives 20 (4), 219-232.

Leeson, E., Stanisstreet, M., Boyes, E. (1997) Year primary children's ideas about cars and the environment Education 3-13, 25 (2), 25-29.

Malatesta, S., Camuffo, M., (2007), Geography, education for sustainable development and primary school curricula: a complex triangle, in: Geographical Views on Education for Sustainable Development, Volume 42 of Geographiedidaktische Forschungen, Sibylle Reinfried, Yvonne Schleicher, Armin Rempfler (Editors), Luzern, Switzerland 2007, 58-65.

McDonough, W, Braungart, M. (2013) The upcycle: Beyond sustainability - Designing for abundance, New York: North Point Press.

Robertson, M., Lee, J.K. (2009) Education for Sustainable Development: Towards Whole School and Community Approaches. In: Williams M., Lee JK. (eds) Schooling for Sustainable Development in Chinese Communities. Schooling for Sustainable Development, vol 1. Springer, Dordrecht

Santulli, C., Lucibello, S. (2018) Experience of Material Tinkering from Waste in the Year 3-Year 5. Year primary School Age Range as an Introduction to Design and Sustainability, Journal of Education and Practice 9, 115126.

Summers, M., Corney, G., Childs, A. (2003) Teaching sustainable development in Year primary schools: An empirical study of issues for teachers, Environmental Education Research 9 (3), 327-346.

Terrenghi, I. et al. (2019). Episode of situated learning to enhance student engagement and promote deep learning: preliminary results in a high school classroom, Frontiers in Psychology, 26 June, https://doi.org/10.3389/fpsyg.2019.01415

Whitley. D. (2012). The idea of nature in Disney animation: from snow white to Wall-E, Ashgate Publishing, Ltd., 2012 - Literary Criticism - 187 pages 
Table 1. Goals and objectives of the experience

\begin{tabular}{|c|c|c|}
\hline Discipline & Goals & Objectives \\
\hline Geography & $\begin{array}{l}\text { Find out the progressive } \\
\text { transformations operated by } \\
\text { humans in natural landscape. }\end{array}$ & $\begin{array}{l}\text { Understand that territory is a space organized and modified by } \\
\text { human activities } \\
\text { Recognize, in your life setting, the functions of different spaces } \\
\text { and their connections, the positive and negative human } \\
\text { interventions and design solutions, practicing the active } \\
\text { citizenship. } \\
\text { Single out problems relative to protection and valorization of } \\
\text { natural and cultural heritage, proposing solutions adapted to your } \\
\text { context of life. }\end{array}$ \\
\hline Science & $\begin{array}{l}\text { Having a caring behavior } \\
\text { towards the school } \\
\text { environment he/she shares } \\
\text { with others; respecting and } \\
\text { appreciating the value of } \\
\text { social and natural } \\
\text { environment. }\end{array}$ & $\begin{array}{l}\text { Observe and interpret the natural transformations of the } \\
\text { environment (due to the action of the Sun, of atmospheric agents, } \\
\text { of water, etc.) and those operated by humans (urbanization, } \\
\text { cultivation, industrialization, etc.). } \\
\text { Recognize in other living organisms, in relation with their } \\
\text { respective environments, needs similar to ours. }\end{array}$ \\
\hline
\end{tabular}
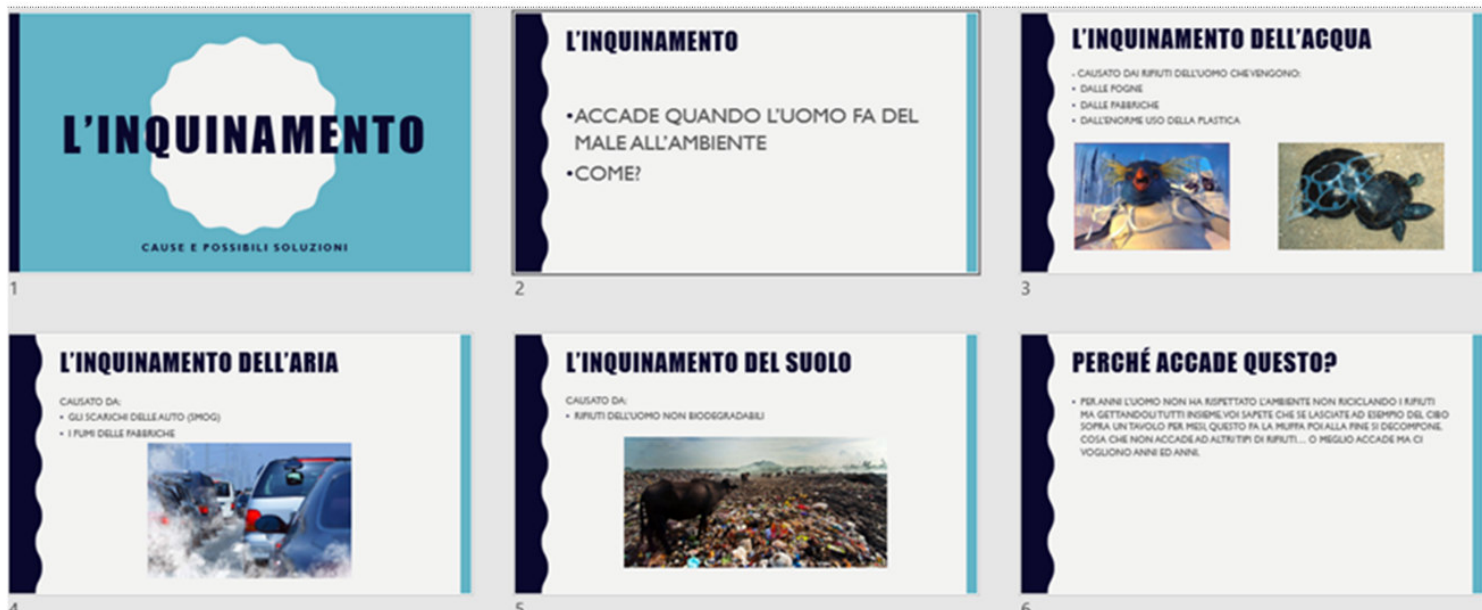

Figure 1. Powerpoint presentation of pollution (inquinamento) of water, air and soil, with final question about how this happens 


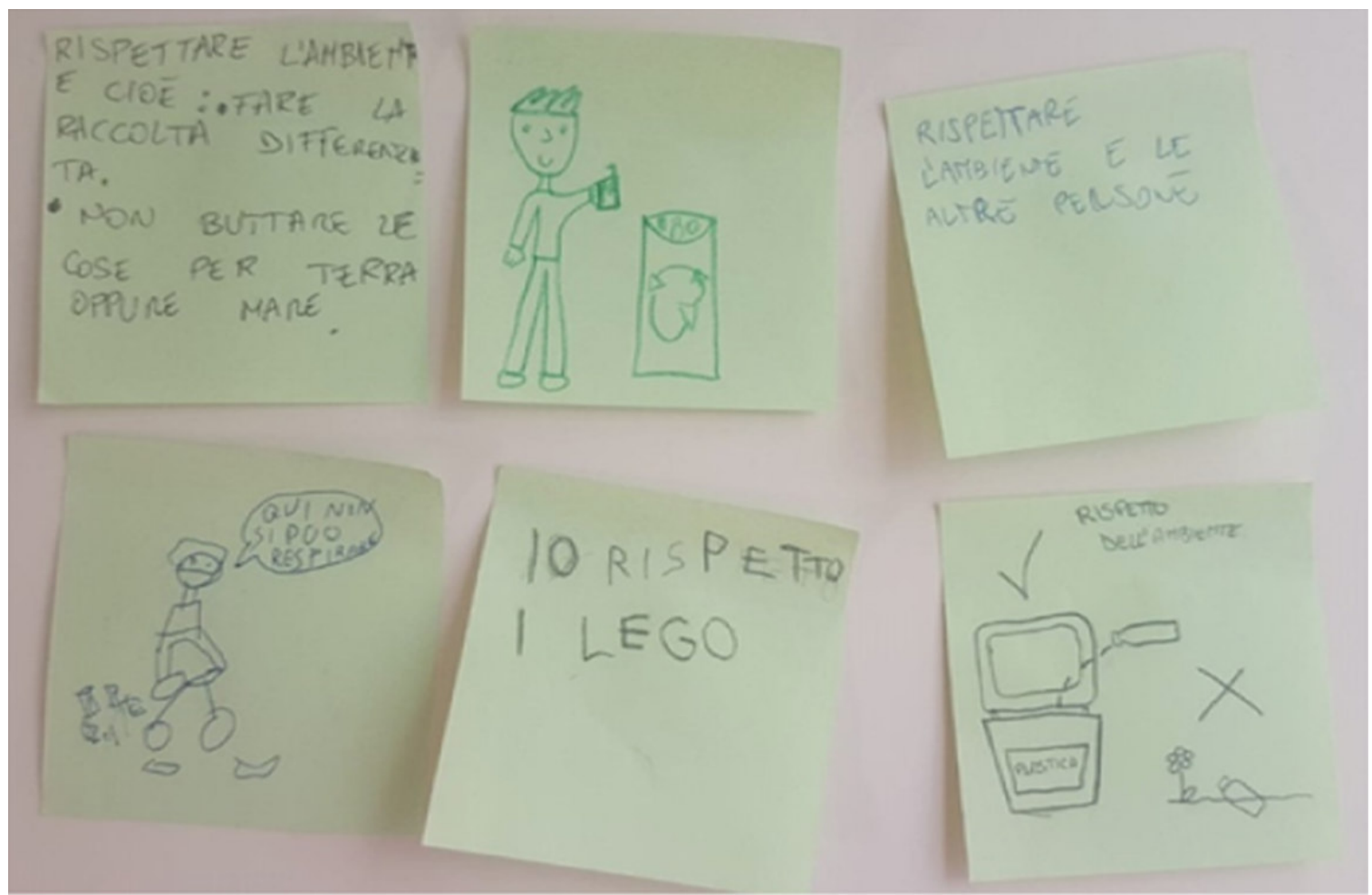

Figure 2. Some post-its on Respect and pollution

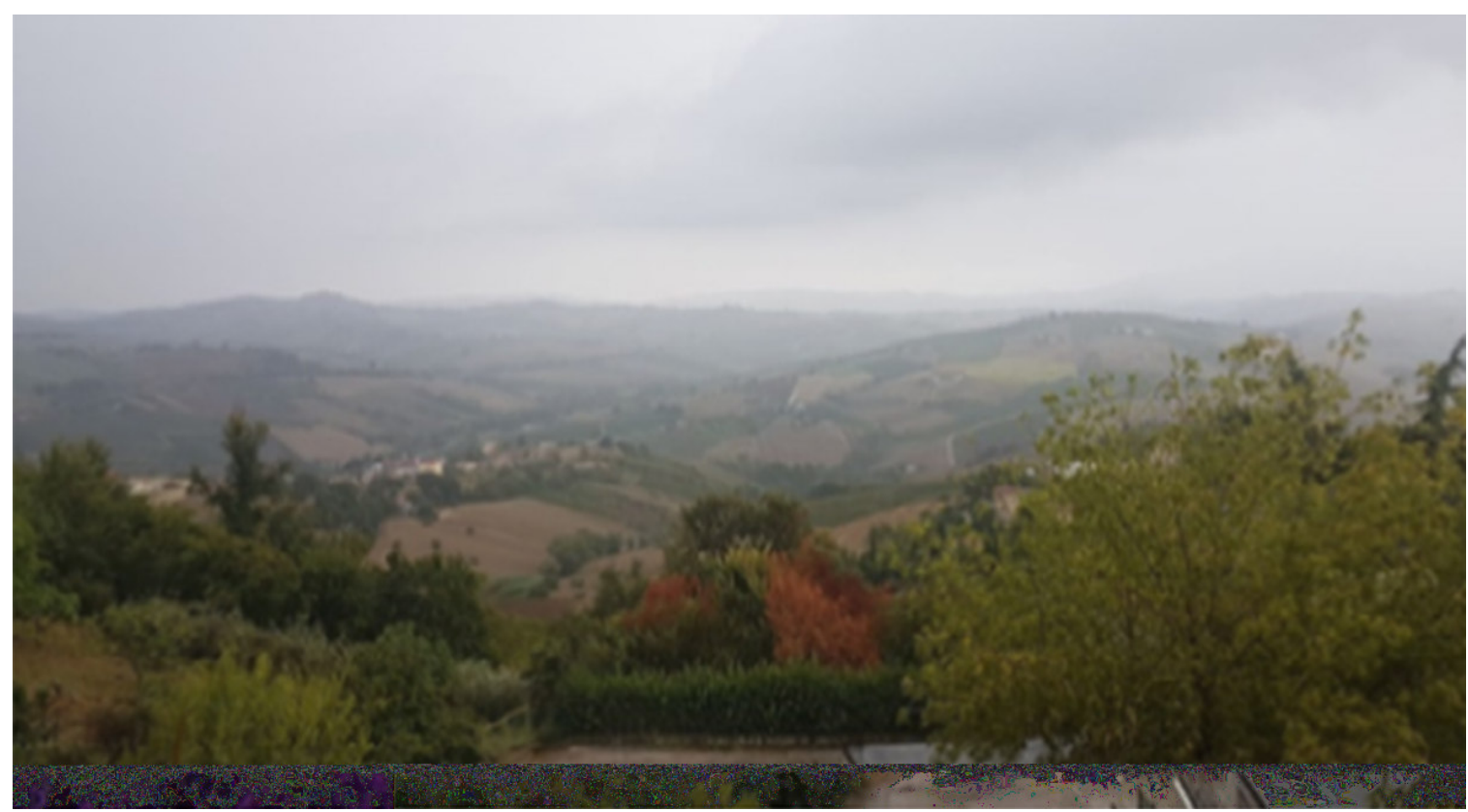

Figure 3. Landscape from the classroom window 

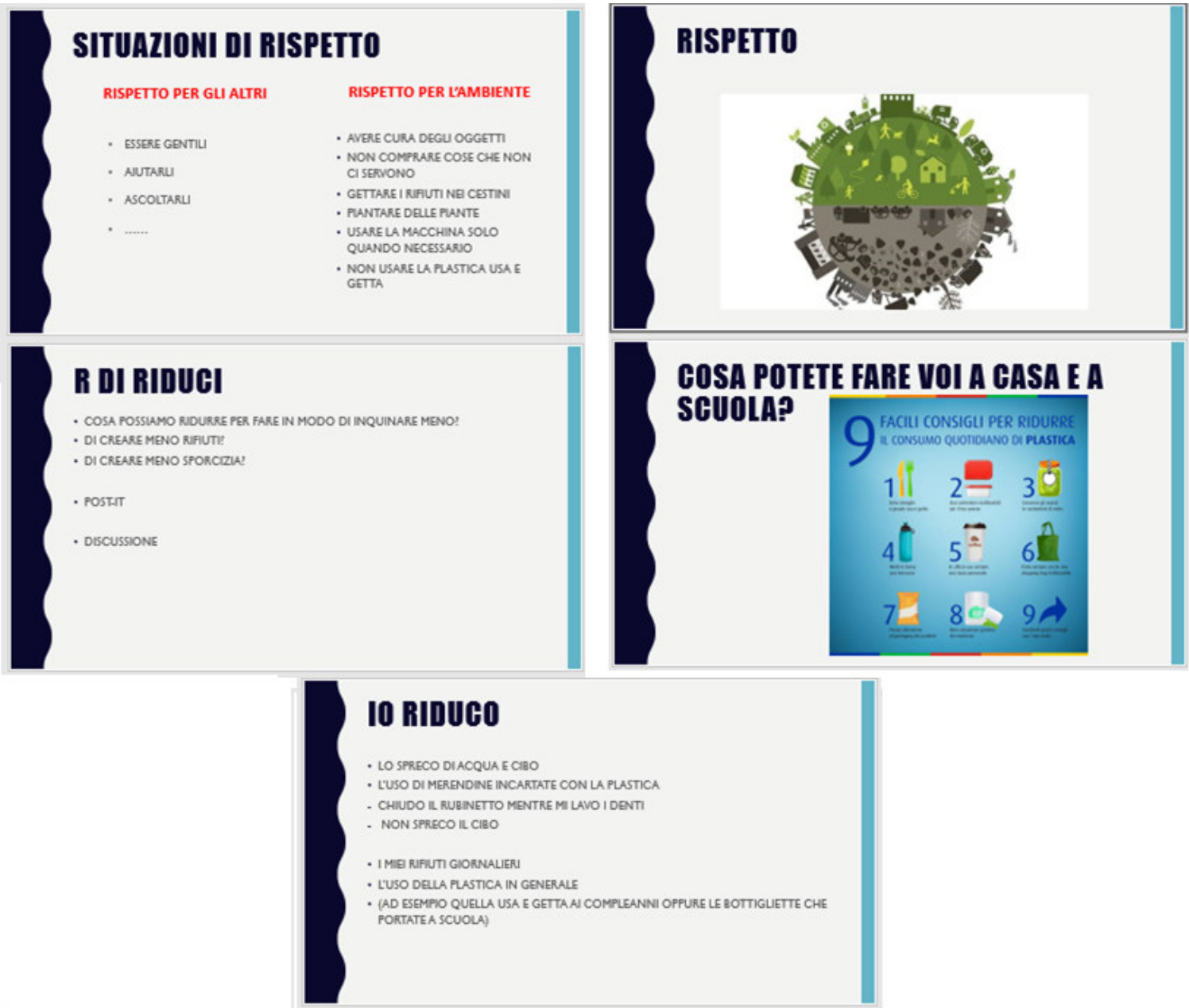

Figure 4. Powerpoint presentation of situation of Respect in correlation with Reduce with a few possible pieces of advice on good practices
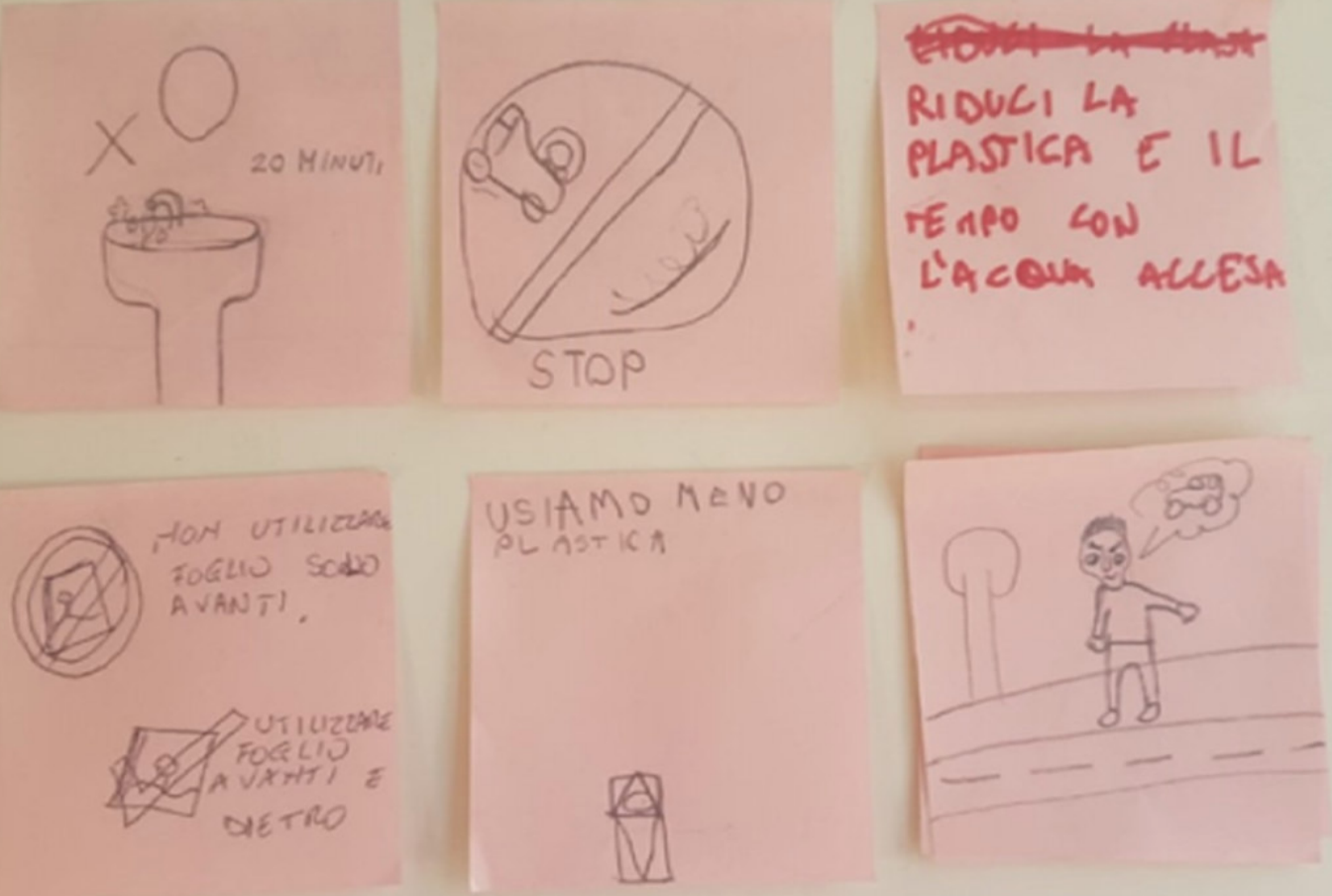

Figure 5. Some post-its on Reduce 
Figure 6. Operations for the preparation of Do-It-Yourself recipes

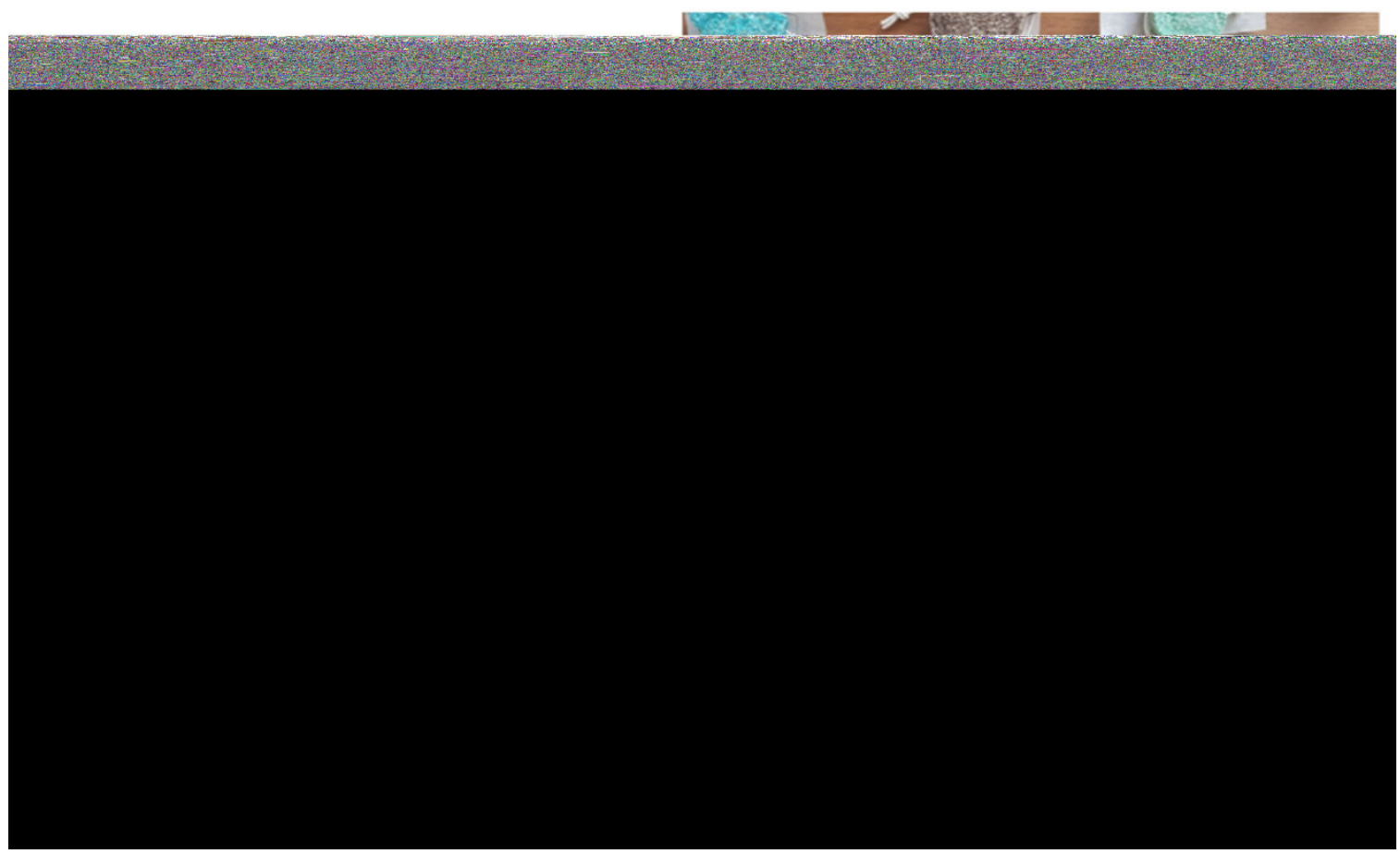

Figure 7. Do-It-Yourself objects obtained 


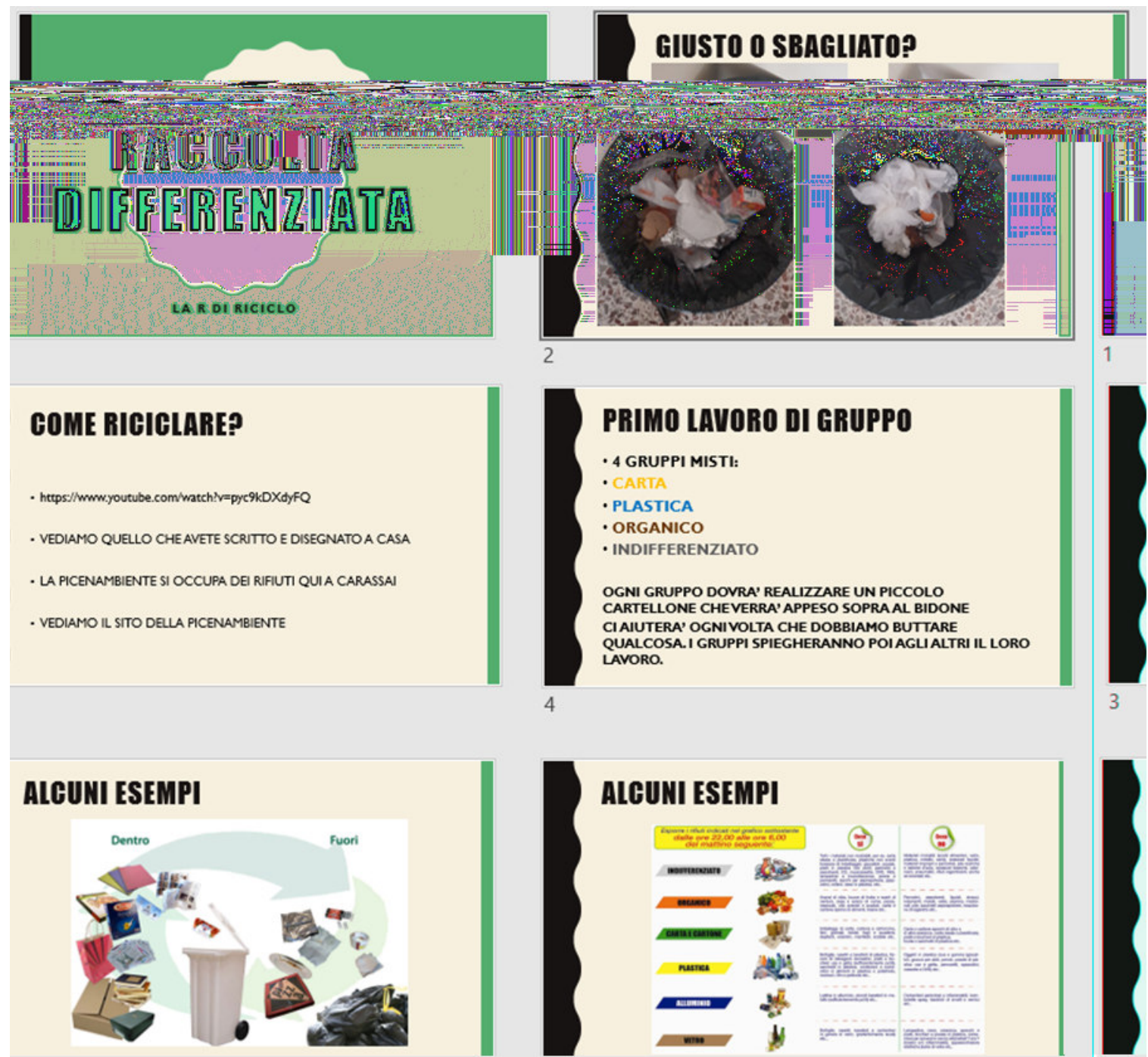

Figure 8. Powerpoint presentation of the local indications about differentiated waste collection and on the relevant work to be done at school

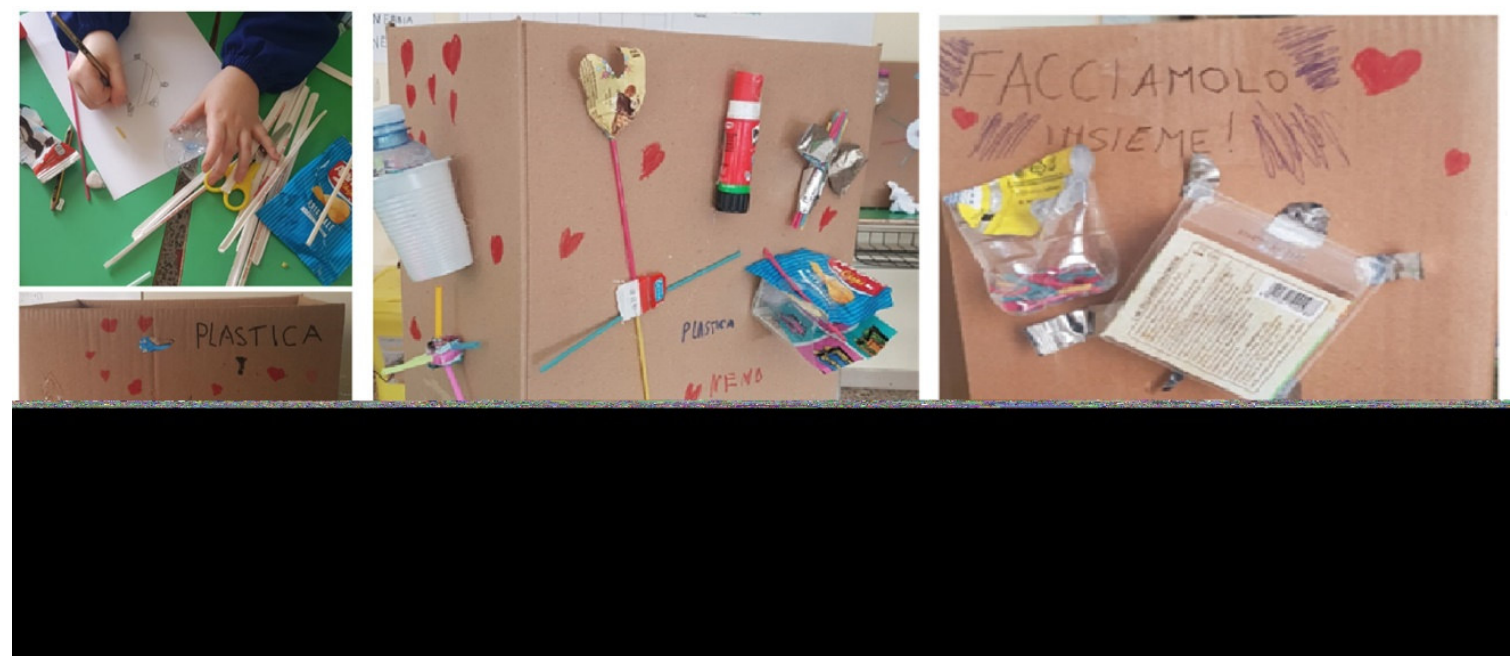

Figure 9. Operations of decoration of the differentiated waste collection by non-recyclable objects 

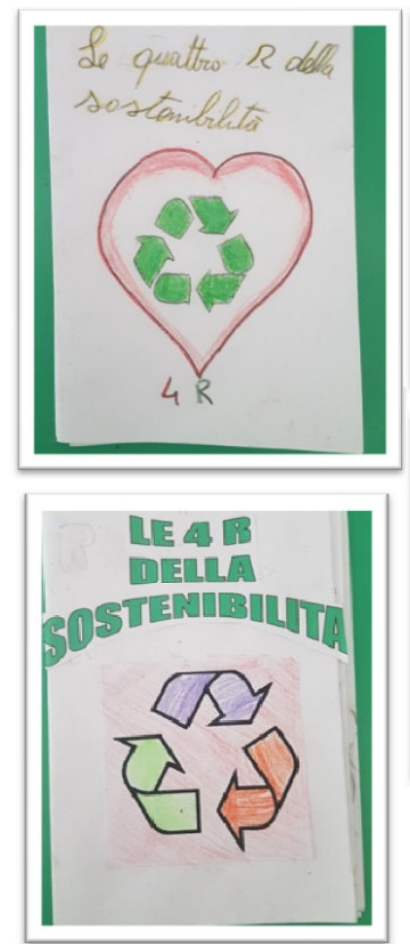
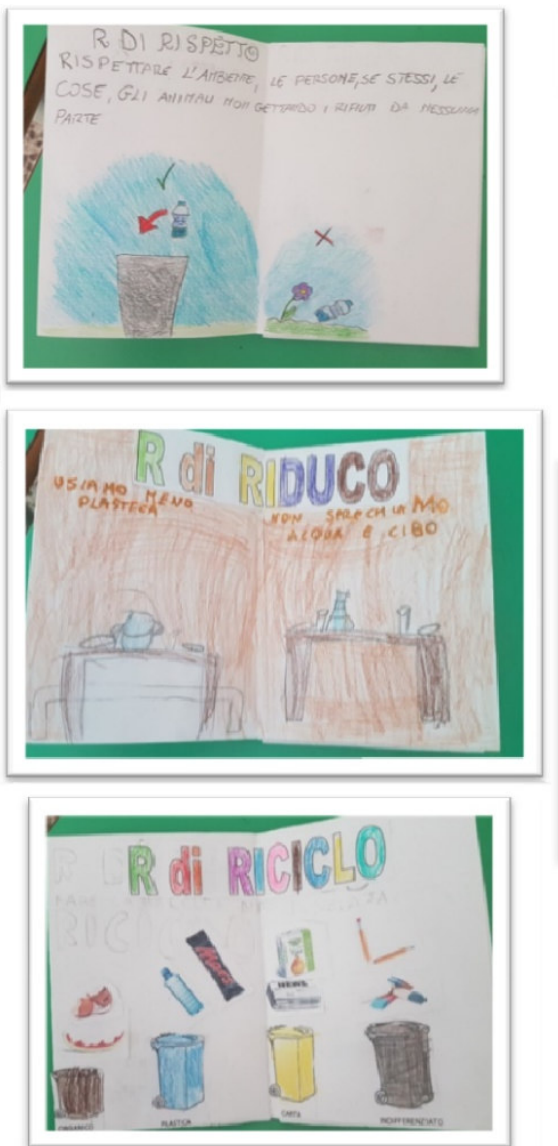
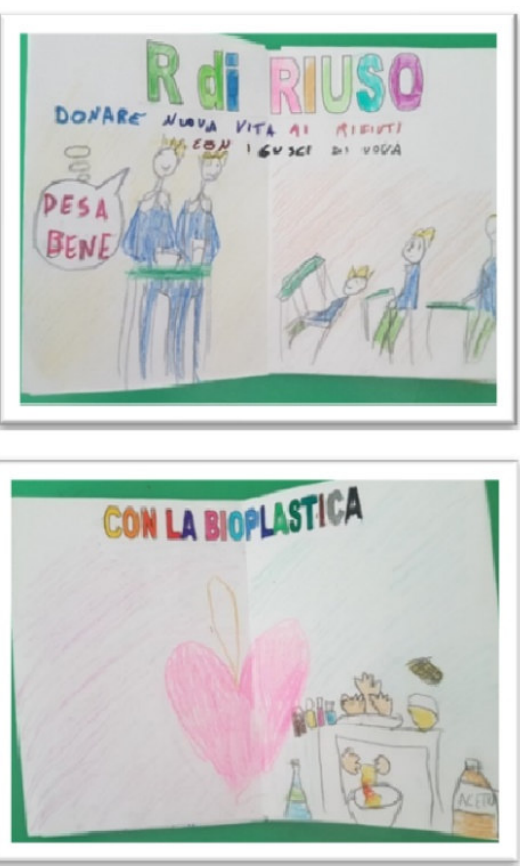

Figure 10. An example of booklet for the "authentic task" on the 4Rs 